\title{
ANÁLISE COMPARATIVA DE NUTRIENTES FUNCIONAIS EM MORANGOS DE DIFERENTES CULTIVARES DA REGIÃ̃O DE LAVRAS-MG ${ }^{1}$
}

\author{
DENISE ALVARENGAROCHA ${ }^{2}$, CELESTE MARIAPATTO DE ABREU $^{3}$, ANGELITADUARTE CORRÊA $^{4}$, \\ CUSTÓDIO DONIZETE DOS SANTOS ${ }^{5}$, ELLEM WALESKA NASCIMENTO DA FONSECA ${ }^{6}$
}

RESUMO - O morango é um pseudofruto muito apreciado pela população brasileira, e seu cultivo vem sendo implantado na região de Lavras. É um alimento funcional, pois, além das suas propriedades nutricionais, também possui substâncias ativas, que mantêm ou melhoram a saúde do organismo humano. O objetivo deste trabalho foi avaliar alguns compostos do morango que tenham efeitos benéficos para a saúde humana, em diferentes cultivares da região de Lavras-MG. O delineamento utilizado foi o inteiramente casualizado, com três tratamentos e 7 repetições de 5 frutos cada. Foram colhidos 150 frutos de três cultivares: 'Aroma', 'Oso grande' e 'Toyorrinho', os quais foram selecionados de acordo com o estádio de maturação e ausência de injúrias. Os compostos avaliados foram vitamina $C$, compostos fenólicos e minerais, dentre os quais o potássio, cálcio, magnésio, ferro, cobre, manganês e zinco. Entre as três cultivares, a 'Aroma' foi a que mais se destacou em relação à vitamina $\mathrm{C}$ e potássio; a cultivar 'Oso grande' obteve os maiores teores de cálcio, ferro, manganês, zinco e cobre, e a 'Toyorrinho' apresentou os menores teores dos compostos funcionais estudados.

Termos para indexação: morangos, cultivares, vitamina $\mathrm{C}$, compostos fenólicos e minerais.

\section{COMPARATIVE ANALYSIS OF FUNCTIONAL NUTRIENTS IN STRAWBERRIES OF DIFFERENT CULTIVARS IN THE REGION OF LAVRAS-MG}

\begin{abstract}
The strawberry is a pseudo-fruit highly appreciated by the Brazilian population, and its growing has been being established in the region of Lavras. It is a functional food, because in addition to its nutritional properties, it also has active substances, which maintain or improve the health of the human organism. The aim of this work was to evaluate a few compounds of the strawberry, which have beneficial effects to human health in different cultivars of the region of Lavras-MG. It was used the completely randomized design with three treatments and seven replicates of five fruits each. A hundred and fifty fruits from three cultivars, 'Aroma', 'Oso Grande' and 'Toyorrinho' were harvested; those were selected according to the maturation stage and absence of injuries. The compounds evaluated were vitamin C, phenolic compounds and minerals, among them potassium, calcium and zinc. Among the three cultivars, 'Aroma' was the most stood out in relation to vitamin C and potassium, the cultivate 'Oso Grande' received the greatest levels of calcium, iron, manganese, zinc and copper and 'Toyorrinho' presented the most inferor functional levels of the studied compounds.
\end{abstract}

Index terms: strawberries, cultivars, vitamin C, minerals and phenolic compounds.

\section{INTRODUÇÃO}

O morangueiro é uma planta perene, rasteira, herbácea pertencente à família Rosácea e do gênero Fragaria (Gomes, 2007). A parte comestível é o morango, que é um pseudofruto nãoclimatérico (Chitarra \& Chitarra, 2005) de coloração vermelhobrilhante, odor envolvente, textura e sabor levemente acidificado (Henrique e Cereda, 1999). A coloração do morango é devido às antocianinas, e o seu sabor característico é devido aos ácidos cítrico e málico, e aos açúcares (Silva, 2006).

A cultura encontra-se difundida em regiões de clima temperado e subtropical. No Brasil, os Estados que mais cultivam o morango são Minas Gerais, São Paulo e Rio Grande do Sul, sendo a produção nacional de 40 mil toneladas (Rigon et al., 2002). As principais cultivares utilizadas provêm dos Estados Unidos da América-EUA, onde se destacam a 'Aroma', 'Camarosa', 'Dover', 'Oso Grande' e 'Sweet Charlie', da Espanha
'Milsei-Tudla', e dos programas de melhoramento genético de Instituições Nacionais, como a Empresa Brasileira de Pesquisa Agropecuária- Embrapa Clima Temperado 'Bürkley', 'Santa Clara' e 'Vila Nova', e do Instituto Agronômico de Campinas - IAC (Oliveira et al., 2005).

Na região de Lavras (MG), cultivam-se a 'Aroma', 'Oso Grande' e 'Toyorrinho'. A 'Aroma' teve origem na Universidade da Califórnia-EUA, cultivar de dia neutro, fruto com bom tamanho, precoce, coloração vermelho-brilhante, bom sabor, vigor médio, sendo indicada para o cultivo de verão (Embrapa, 2007). 'Oso grande' teve origem na Universidade da Califórnia-EUA, no ano de 1987. Esta é uma cultivar de dias curtos, fruto grande, firme, doce, com baixa acidez.

A 'Toyorrinho' é de origem japonesa, tendo sido criada em 1975. O seu fruto é de excelente aroma e sabor, e a produtividade é média (Silva, 2006).

As substâncias ativas presentes em frutos são capazes

${ }^{1}$ (Trabalho 282-07). Recebido em: 28-11-2007. Aceito para publicação 08-08-2008.

${ }^{2}$ Farmacêutica, doutoranda em Agroquímica, pela Universidade Federal de Lavras (UFLA)- deniserocha3@ hotmail.com

${ }^{3,4}$ Professora associada do Departamento de Química da Universidade Federal de Lavras(UFLA).Bolsista CNPQ Brasil. Caixa Postal 3037, 37.200.000Lavras-MG. celeste@ufla.br e angelita@ufla.br.

${ }^{5}$ Professor titular do Departamento de Química da Universidade Federal de Lavras(UFLA) Caixa Postal 3037, 37.200.000-Lavras-MG.santoscd@ufla.br ${ }^{6}$ Doutoranda em Agroquímica, pela Universidade Federal de Lavras (UFLA).elem.waleska@ig.com.br 
de atuar na prevenção e/ou na cura de várias doenças.

Dentre as propriedades do morango, destacam-se a sua ação antioxidante, a capacidade de reduzir a suscetibilidade a infecções, o seu efeito diurético e sua atividade antiinflamatória em reumatismo e gota.

O morango é rico em vitamina $\mathrm{C}$, uma vitamina hidrossolúvel de extrema importância para o organismo humano e encontrada em frutos cítricos. Desempenha um papel fundamental no desenvolvimento e regeneração dos músculos, pele, dentes e ossos, na formação do colágeno, na regulação da temperatura corporal, na produção de diversos hormônios e no metabolismo em geral (Andrade et al., 2002). Além disso, é um poderoso antioxidante, sendo usado para transformar os radicais livres de oxigênio em formas inertes. $\mathrm{O}$ seu poder antioxidante deve-se ao grupo diol (-COH-COH-), o qual pode oxidar-se e formar o ácido desidroascórbico (Silva \& Mura, 2007), e a enzima envolvida nesse processo é o ácido ascórbico oxidase (Braverman, 1967). A carência severa torna o organismo vulnerável a doenças mais graves, como, por exemplo, o escorbuto. Entretanto, consumida em altas doses, pode provocar efeitos colaterais, tais como: diarréia, dor abdominal e cálculos renais em pessoas geneticamente predispostas.

Além dessa vitamina, o morango possui compostos fenólicos. Esses grupos raramente são encontrados na forma livre, podendo estar ligados a: proteínas, lipídeos, terpenóides, ácido hidroxicinâmico, carboidratos e pode formar éster com ácidos orgânicos (Kays, 1991) Os compostos fenólicos agem também como antioxidantes naturais, possuem atividade anticarcinogênica, menor incidência de doenças coronarianas e ação bactericida e fungicida (Curti, 2003; De Angelis, 2001).

Os minerais são elementos essenciais para o organismo humano, por isso devem ser obtidos naturalmente através dos alimentos. Dentre os minerais, encontram-se o cálcio $(\mathrm{Ca})$, potássio $(\mathrm{K})$, magnésio $(\mathrm{Mg})$, manganês $(\mathrm{Mn})$, ferro $(\mathrm{Fe})$, zinco $(\mathrm{Zn})$ e cobre $(\mathrm{Cu})$.

O cálcio é o mais abundante mineral do indivíduo, é essencial na construção e manutenção dos ossos e dentes, mas atuam também na função dos hormônios protéicos, auxilia na transferência de íons através das membranas, atua na liberação de neurotransmissores das junções sinápticas e regula os batimentos cardíacos (Hardman, 1996; Silva \& Mura, 2007).

O magnésio é o segundo mineral mais abundante encontrado nos fluidos intracelulares, exercem papel fundamental em diversas reações intracelulares, incluindo produção e consumo de energia, além das reações enzimáticas, como a fosforilação da glicose e suas ramificações na via glicolítica (Nelson e Cox, 2002).

O papel metabólico do manganês é considerável, pois ele ativa numerosas enzimas envolvidas na síntese do tecido conjuntivo, na regulação da glicose, na proteção das células contra os radicais livres e nas atividades neuro-hormonais. É absorvido no intestino delgado, atinge o fígado e daí é distribuído para diversas partes do organismo (Silva \& Mura, 2007).

O Ferro está presente em vários compartimentos no organismo na quantidade de 3 a $4 \mathrm{~g}$, e encontra-se principlamente no sangue, devido à hemoglobina que contém cerca de $70 \%$ de todo o ferro corporal, e sua principal função esta relacionada com o transporte de oxigênio (Rang et al., 2001).

O zinco está presente em todos os tecidos, órgãos, fluidos e secreções, mas em maior quantidade nos músculos esqueléticos e ossos. Esse mineral é essencial para a função de mais de 300 enzimas, participando do metabolismo de carboidratos, proteínas, lipídeos e ácidos nucléicos (Silva \& Mura, 2007).

O cobre é o terceiro elemento-traço mais abundante depois do ferro e do zinco. Exerce papel catalítico e promove mobilização do ferro para a síntese de hemoglobina (Andrade, 2002). Já o potássio e a água, constituintes também do morango, apresentam um leve efeito diurético que poderá ser benéfico para as pessoas que fazem retenção de líquidos no corpo ou em casos de hiperuricemia e hipertensão (De Angelis, 2001).

Hoje em dia, a procura por melhor qualidade de vida faz com que as pessoas associem melhor os alimentos com a finalidade de obter vantagens terapêuticas. $\mathrm{O}$ objetivo deste trabalho foi avaliar alguns compostos do morango que tenham efeitos benéficos para a saúde humana, comparando-os em diferentes cultivares de morango da região de Lavras-MG.

\section{MATERIAL E MÉTODOS}

Os morangos das cultivares 'Aroma', 'Oso Grande' e 'Toyorrinho' foram adquiridos em um viveiro comercial de Itutinga (MG), situado a 910m de altitude, e nas coordenadas geográficas de 210 41' 15" de latitude Sul e 44 41' 15" de longitude W.Gr. (IBGE, 1959). No mesmo dia, foram colhidos 50 frutos de cada cultivar, no estádio maduro, sendo em seguida transportados ao laboratório de bioquímica do Departamento de Química da Universidade Federal de Lavras (UFLA), onde foram selecionados 35 frutos de cada cultivar. Os frutos foram picados, embalados, identificados e armazenados em freezer $\left(-20^{\circ} \mathrm{C}\right.$ a -10 ${ }^{\circ} \mathrm{C}$ ) até as análises. A vitamina $\mathrm{C}$ foi extraída e doseada no dia da colheita.

Utilizou-se o delineamento experimental inteiramente casualizado (DIC), com três tratamentos, 7 repetições com 5 frutos cada. Os resultados foram submetidos à análise de variância, por meio do programa SANEST. As médias foram comparadas entre si pelo teste de Tukey, a 5\% de significância.

\section{Características avaliadas nos frutos} ascórbico

Determinação da vitamina $\mathrm{C}$ a partir dos teores de ácido

As determinações de ácido ascórbico foram realizadas de acordo com a metodologia descrita por Strohecker \& Henning (1967), utilizando-se da solução de ácido oxálico $2 \%$ para a extração.

\section{Determinação de compostos fenólicos}

A extração dos compostos fenólicos foi feita segundo Goldstein \& Swain (1963) e dosados pelo método de Folin-Denis (AOAC, 2000). 
Determinação dos teores de potássio, cálcio, manganês, magnésio, ferro, cobre e zinco

As amostras foram analisadas em extratos obtidos mediante a digestão nitroperclórica e leitura em espectrofotômetro de absorção atômica, conforme método descrito por Malavolta (1997).

\section{RESULTADOS E DISCUSSÃO}

\section{Vitamina C}

A cultivar 'Aroma' apresentou maior teor de vitamina C em relação às cultivares 'Oso Grande' e 'Toyorrinho' (Tabela1).

O morango é uma fruta cítrica com grande teor de vitamina C, mas, dependendo da variedade, esse teor pode variar. São apresentados na literatura dados relativos de vitamina $\mathrm{C}$, variando de 39 a $89 \mathrm{mg} / 100 \mathrm{~g}$ de polpa, sendo o valor médio, para morangos, de $60 \mathrm{mg} / 100 \mathrm{~g}$ de fruta (Domingos, 2000). As três cultivares apresentaram valores de vitamina $\mathrm{C}$ de acordo com os citados na literatura. A necessidade diária de vitamina $\mathrm{C}$ varia conforme idade e condições de saúde. De acordo com a Agência Nacional de Vigilância Sanitária (ANVISA), as recomendações de ingestão de vitamina C, segundo a RDC n.268/2005, é de $45 \mathrm{mg} / \mathrm{dia}$ (ANVISA, 2007). Considerando a RDC n.268/2005, bastaria ingerir 55,4g de morangos frescos da cultivar 'Aroma' para adquirir a quantidade diária necessária de vitamina $\mathrm{C}$, seguida de $61,52 \mathrm{~g}$ para a cultivar 'Oso Grande' e 78,75g para a 'Toyorrinho'. Acultivar Aroma destacou-se em relação ao teor de Vitamina C, pois ingerindo menor quantidade de morangos, obtêm-se os nutrientes diários e, provavelmente, os efeitos benéficos da vitamina $\mathrm{C}$, mantendo a homeostasia do organismo humano e prevenindo doenças.

\section{Determinação de compostos Fenólicos}

Não houve diferença significativa nas três cultivares analisadas neste estudo, conforme mostrado na Tabela 2.

Os compostos fenólicos são detectados principalmente em frutas verdes, pois durante o amadurecimento ocorre a condensação dos fenólicos solúveis, tornando-os insolúveis por se ligarem fortemente a outros compostos celulares, não sendo, portanto, detectados pela técnica de extração (Chitarra \& Chitarra, 2005). Como neste estudo os morangos foram coletados no estádio maduro, não eram esperadas grandes quantidades de fenólicos.

De acordo com Kuskoski \& Morales (2006), a quantidade total de fenólicos na polpa de morango congelada é de 132,0 mg de ácido tânico/100 g de polpa, que corresponde a $0,132 \%$. O teor considerado nocivo à saúde é acima $1 \%$ (Corrêa et al., 2000). Todas as cultivares estudadas apresentaram teores de compostos fenólicos totais abaixo do considerado nocivo à saúde, sendo, portanto, benéficos a saúde nesse percentual encontrado, já que agem como antioxidantes, prevenindo a ocorrência de algumas doenças, como as coronarianas.

\section{Determinação dos teores dos minerais}

Os minerais são compostos importantes para a manutenção das funções essenciais ao organismo humano. Os resultados de minerais nas três cultivares encontram-se na Tabela 3.

Observou-se que a cultivar 'Oso Grande' foi a que obteve o maior teor de cálcio, porém o IDR (Ingestão diária recomendada) desse íon divalente é de $1.000 \mathrm{mg} / \mathrm{dia}$, ou seja, o morango não é uma fonte indicada para se obter cálcio, já que seria necessário ingerir em torno de 555,5g de morango para adquirir a quantidade diária e seus efeitos benéficos em relação à estrutura óssea.

Em relação ao potássio e ao magnésio, a cultivar 'Aroma' obteve maiores valores, sendo que o ideal para a ingestão diária é de $4,6 \mathrm{~g}$ para o potássio e $260 \mathrm{mg}$ /dia para o magnésio em indivíduos adultos. Isso mostra que seria necessário ingeria 528,73 g de morangos para o potássio manter o balanço e a distribuição de água, no equilíbrio osmótico, no equilíbrio ácido-base e na regulação da atividade neuromuscular, e 173,33g para o magnésio, que desempenha papel de importância na atividade de muitas coenzimas e em reações que dependem da ATP.

Observa-se, na Tabela 4, que a cultivar 'Oso Grande' apresentou maiores teores de ferro, manganês, zinco e cobre.

O IDR de ferro para adultos é de $14 \mathrm{mg}$, segundo a ANVISA 2005, ou seja, seria necessário ingerir em torno de 225,73 $\mathrm{g}$ de morangos da cultivar 'Oso Grande' para manter a quantidade ideal de hemoglobinas em nosso organismo.

Em relação ao manganês seriam necessários $2,3 \mathrm{mg} / \mathrm{dia}$; comparando com o teor encontrado no morango da 'Oso Grande', teríamos de ingerir 43,61g de morangos para garantirmos o seu papel metabólico considerável, pois ele ativa numerosas enzimas implicadas na síntese do tecido conjuntivo, na regulação da glicose, na proteção das células contra os radicais livres.

O zinco é um elemento-traço necessário a todas as células do corpo, sendo o seu IDR de $7 \mathrm{mg}$, então teremos de ingerir 427,61 g para obter as quantidades diárias e garantir sua presenças nas enzimas de vários metabólitos.

O cobre é também um elemento traço importante para o organismo humano, o seu IDR é de $900 \mu \mathrm{g} / \mathrm{dia}$. Observa-se na Tabela 4 que seu teor em morangos da cultivar 'Oso-Grande' foi de $5,81 \mathrm{~g} / \mathrm{kg}$, ou seja, será necessário ingerir $176,47 \mathrm{~g}$ de morangos dessa cultivar. Com a ingestão adequada, o cobre exerce várias funções, como a mobilização de ferro para a síntese de hemoglobinas, componentes de várias enzimas, como a citocroma C oxidase (Andrade et al., 2002).

Os minerais são essenciais para a saúde, sendo que o seu teor pode variar quantitativamente em diferentes cultivares, mesmo quando são cultivadas nas mesmas condições.

TABELA 1-Teores médios de vitamina C (mg de ácido ascórbico/ $100 \mathrm{~g}$ de polpa) em três cultivares de morango.

\begin{tabular}{cc}
\hline Cultivar & Média \\
\hline & $(\mathrm{mg} / 100 \mathrm{~g})$ \\
'Aroma' & $81,14 \mathbf{A}$ \\
'Oso Grande' & $73,14 \mathbf{B}$ \\
'Toyorrinho' & $57,14 \mathbf{C}$ \\
\hline CV\% & 4,290 \\
\hline
\end{tabular}

Médias seguidas por letras distintas diferem entre si, pelo teste de Tukey, a $5 \%$ de probabilidade. 
TABELA 2 - Teores médios de compostos fenólicos (mg de ácido tânico/100 g de polpa) em três cultivares de morango.

\begin{tabular}{cc}
\hline Cultivar & Média \\
\hline & $(\mathrm{mg} / 100 \mathrm{~g})$ \\
$202,87 \mathbf{A}$ \\
'Aroma' & $222,85 \mathbf{A}$ \\
'Toyo Grande' & $217,14 \mathbf{A}$ \\
\hline
\end{tabular}

Médias seguidas por letras distintas diferem entre si, pelo teste de Tukey, a 5\% de probabilidade.

TABELA 3 - Teores médios de minerais (g/kg) em três cultivares de morango.

\begin{tabular}{cccc}
\hline Cultivares & Cálcio & Potássio & Magnésio \\
\hline & $(\mathrm{g} / \mathrm{Kg})$ & $(\mathrm{g} / \mathrm{Kg})$ & $(\mathrm{g} / \mathrm{Kg})$ \\
'Aroma' & $1,7 \mathbf{~ B}$ & $8,7 \mathbf{A}$ & $1,5 \mathbf{A}$ \\
'Oso Grande' & $1,8 \mathbf{A}$ & $8,4 \mathbf{~ B}$ & $1,4 \mathbf{~ B}$ \\
'Toyorrinho' & $1,6 \mathbf{C}$ & $7,6 \mathbf{C}$ & $1,1 \mathbf{C}$ \\
\hline CV \% & 9,254 & 9,312 & 9,251 \\
\hline
\end{tabular}

Médias seguidas por letras distintas nas colunas diferem entre si, pelo teste de Tukey, a 5\% de probabilidade.

TABELA 4 - Teores médios de minerais (mg/Kg) em três cultivares de morango.

\begin{tabular}{ccccc}
\hline Cultivares & Ferro & Manganês & Zinco & Cobre \\
\hline & $(\mathrm{mg} / \mathrm{Kg})$ & $(\mathrm{mg} / \mathrm{Kg})$ & $(\mathrm{mg} / \mathrm{Kg})$ & $(\mathrm{mg} / \mathrm{Kg})$ \\
'Aroma' & $55,87 \mathbf{~ B}$ & $43,85 \mathbf{C}$ & $14,14 \mathbf{B}$ & $5,35 \mathbf{~ B}$ \\
'Oso Grande' & $62,02 \mathbf{A}$ & $52,74 \mathbf{A}$ & $16,37 \mathbf{A}$ & $5,81 \mathbf{A}$ \\
'Toyorrinho' & $51,80 \mathbf{C}$ & $46,32 \mathbf{~ B}$ & $12,78 \mathbf{C}$ & $5,28 \mathbf{C}$ \\
\hline CV \% & 4,139 & 1,325 & 1,286 & 4,018 \\
\hline
\end{tabular}

Médias seguidas por letras distintas nas colunas diferem entre si, pelo teste de Tukey, a 5\% de probabilidade.

\section{CONCLUSÃO}

Dentre as cultivares estudadas, a 'Aroma' obteve maiores teores de vitamina C e potássio, a cultivar 'Oso-Grande' obteve os maiores teores de cálcio, ferro, manganês, zinco e cobre, e a 'Toyorrinho' apresentou menores teores dos compostos funcionais estudados.

\section{REFERÊNCIAS}

ANVISA - AGÊNCIA NACIONAL DE VIGILÂNCIA SANITÁRIA-ANVISA. Portaria n.33/98. Disponível em: <http:/ / www.anvisa.gov.br/legis/portarias/33_98.htm>. Acesso em: 10 out. 2007 .

ANDRADE, R. S. G. de ; DINIZ, M. C. T.; NEVES, E. A.; NÓBREGA, J.A. Determinação e distribuição de ácido ascórbico em três frutos tropicais. Eclética Química, São Paulo, v.27, n.especial, 2002.

AOAC-ASSOCIATION OFFICIALANALYTICALCHEMISTRY. Official methods of analysis of the Association of Official Analytical Chemistry. $12^{\text {th }}$ ed. Washington, 2000.1015p.
BRAVERMEN, J. B. S. Introduction a la bioquimica de los alimentos. Barcelona: Omega, 1967. cap. 14. p 206-241.

CHITARRA, M. I. F.; CHITARRA, A. B. Pós-colheita de frutos e hortaliças: fisiologia e manuseio. Lavras: ESAL/FAEPE, 2005. 735 p.

CORRÊA, AD.; ABREU, C. M. P. de; SANTOS, C. D.; RIBEIRO, L. J. Determinação de alguns constituintes químicos de interesse nutricional da fruta-de-lobo (Solanum lycocarpum St.Hil.) .Ciências agrotécnicas, Lavras, v.24, n.1, p.130-135, 2000.

CURTI, F. Efeito da Maçã 'Gala' (Malus domestica Bork), na liperdemia de ratos hipercolesterolêmicos. 2003. $65 \mathrm{f}$. Dissertação (Mestrado em Ciência e Tecnologia de Alimentos) Escola Superior de Agricultura "Luiz de Queiroz" Universidade de São Paulo, Piracicaba, 2003.

DEANGELIS, R. C. Importância de alimentos vegetais na proteção da saúde: fisiologia da nutrição protetora e preventiva de enfermidades degenerativas. São Paulo: Atheneu, 2001. 295p.

DOMINGOS, D.M. Efeito da radiação gama e embalagem na conservação de morangos 'Toyonoka' armazenados sob 
refrigeração. 2000. 60 f. Dissertação (Mestrado em Ciência dos Alimentos) - Escola Superior de Agricultura Luís de Queiroz, Universidade de São Paulo, Piracicaba, 2000.

EMBRAPA - EMPRESA BRASILEIRA DE PESQUISA AGROPECUÁRIA. Sistema de produção de morango. Disponível em: <http://www.cpact.embrapa.br/publicacoes/catalogo/tipo/ sistemas/morango/cap08.htm>. acesso em: 20 set. 2007

GOLDSTEIN, J. L.; SWAIN, T. Changes in tannins in ripening fruits. Phytochemistry, Oxcoford, v.2, p.371-383, 1963.

GOMES, P. Fruticultura brasileira. 13.ed. São Paulo: Nobel, 2007. p.342-348

HARDMAN, J. G.; MOLINOFF, P. B.; GILMAN, A. G. As Bases farmacológicas da terapêutica. 9. ed. México: Mc Graw-Hill, 1996. cap.60, p. 1103 .

HENRIQUE, C.M. ; CEREDA, M. P.Utilização de biofilmes na conservação pós-colheita de morango (Fragaria Ananassa Duch) cv IAC Campinas. Ciência e Tecnologia em Alimentos, Campinas,v.19, n.2, p.270-276, 1999.

IBGE - Instituto Brasileiro de Geografia e Estatística. Enciclopédia dos municípios Brasileiros. Rio de Janeiro, 1959. 670 p.

KAYS, Stanley J. Postharvest phisiology of perishable plant products .New York: Van Nostrand Reinhold, 1991. 532p.

KUSKOSKI, E.M.; ASUERO, A. G.; MORALES, M.A.; FETT, R. Frutos tropicais silvestres e polpas de frutas congeladas: atividade antioxidante, polifenóis e antocianinas. Ciência Rural, Santa Maria, v.36, n.4, 2006.
MALAVOLTA, E. Avaliação do estado nutricional das plantas. 2. ed. Piracicaba: Potafós, 1997.

NELSON, D. L.; COX. M. M. Lehninger princípios de bioquímica. 3. ed. São Paulo: Sarvier, 2002. p.233

OLIVEIRA, R.P.; NINO, A.F.P.; SCIVITTARO, W.B. Mudas certificadas de morangueiro: maior produção e melhor qualidade da fruta. A Lavoura, Rio de Janeiro, v.108, n.655, 2005.

RANG, H. P.; DALE, M. M.; RITTER, J. M. Farmacologia. Rio de Janeiro: Guanabara Koogan, 2001. 323-324p.

RIGON, L.; CORRÊA, S.; REETZ, E.; VENCATO, A.; ROSA, G.R.; BELING, R.R. Pequenas frutas. Anuário Brasileiro da Fruticultura, Santa Cruz do Sul, v.1, n.1, p.90-97, 2005.

SILVA, P.A. Qualidade de morangos cultivados na região de Lavras-MG, armazenados em temperatura ambiente. $2006.71 \mathrm{f}$. Dissertação (Mestrado em Agroquímica) -Universidade Federal de Lavras, Lavras, 2006.

SILVA, S. M.S.; MURA J.D.P. Tratado de alimentação, nutrição e dietoterapia. São Paulo: Roca, 2007. p.77-112.

STROHECKER, R.; HENNIG, H. M. Análises de vitaminas: métodos comprobados. Madrid: Paz Montalvo, 1967. 428p. 